\title{
RISK OF PERITONITIS DURING PERITONEAL DIALYSIS IN CARRIERS OF Staphylococcus aureus AND COAGULASE-NEGATIVE STAPHYLOCOCCI
}

\author{
BATALHA J. E. N. (1, 2), CARAMORI J. C. T. (1), CORRENTE J. E. (3), \\ MONTELLI A. C. (1), BARRETTI P. (1), CUNHA M. L. R. S. (2)
}

(1) Department of Clinical Medicine, Botucatu School of Medicine, São Paulo, University, UNESP, Botucatu, São Paulo State, Brazil; (2) Department of Microbiology and Immunology, Institute of Biosciences, UNESP, Botucatu, São Paulo State, Brazil; (3) Department of Biostatistics, Institute of Biosciences, UNESP, Botucatu, São Paulo, Brazil.

ABSTRACT: The presence of Staphylococcus aureus in the nasal cavities and pericatheter skin of peritoneal dialysis patients put them at high risk of developing peritonitis. However, it is not clear whether the presence of coagulase-negative staphylococci (CNS) in the nasal passages and skin of patients is related to subsequent occurrence of peritoneal infection. The aim of the present study was to verify the relationship between endogenous sources of $S$. aureus and CNS and occurrence of peritonitis in patients undergoing peritoneal dialysis. Thirty-two patients on peritoneal hemodialysis were observed for 18 months. Staphylococcus species present in their nasal passage, pericatheter skin and peritoneal effluent were identified and compared based on drug susceptibility tests and dendrograms, which were drawn to better visualize the similarity among strains from extraperitoneal sites as well as their involvement in the causes of infection. Out of 288 Staphylococcus strains isolated, 155 (53.8\%) were detected in the nasal cavity, $122(42.4 \%)$ on the skin, and $11(3.8 \%)$ in the peritoneal effluent of patients who developed peritonitis during the study. The most frequent Staphylococcus species were CNS (78.1\%), compared with S. aureus (21.9\%). Among CNS, S. epidermidis was predominant $(64.4 \%)$, followed by $S$. warneri $(15.1 \%)$, S. haemolyticus $(10.7 \%)$, and other species (9.8\%). Seven (64\%) out of 11 cases of peritonitis analyzed presented similar strains. The same strain was isolated from different sites in two (66\%) out of three $S$. aureus infection cases. In the six cases of $S$. epidermidis peritonitis, the species that caused infection was also found in the normal flora. From these, two cases (33\%) presented highly similar strains and in three cases (50\%), it was difficult to group strains as to similarity. Patients colonized with multidrug-resistant $S$. epidermidis strains were more predisposed to infection. Results demonstrated that an endogenous source of S. epidermidis could cause peritonitis in peritoneal dialysis patients, similarly to what has been observed with S. aureus.

KEY WORDS: Staphylococcus aureus, coagulase-negative staphylococci, carriers, peritoneal dialysis, peritonitis.

\section{CORRESPONDENCE TO:}

MARIA DE LOURDES RIBEIRO DE SOUZA DA CUNHA, Departamento de Microbiologia e Imunologia, Instituto de Biociências, Universidade Estadual Paulista, UNESP, Caixa Postal 510, 18618-000, Botucatu, SP, Brasil. Phone: +55 143811 6058. Fax +55 14 3815-3744. Email: cunhamlr@ibb.unesp.br. 
J. E. N. Batalha et al. RISK OF PERITONITIS DURING PERITONEAL DIALYSIS IN CARRIERS OF Staphylococcus aureus AND COAGULASE-NEGATIVE STAPHYLOCOCCI. J. Venom. Anim. Toxins incl. Trop. Dis., 2006, 12, 4, p. 579

\section{INTRODUCTION}

Peritonitis has been the main complication, cause of technical failure and mortality factor for patients undergoing peritoneal dialysis (13). Peritoneal infection rate varies according to the dialysis service, which reflects that different criteria of selection and treatment are used. The continuation of peritoneal dialysis techniques in outpatient clinics has been hindered by failures in the method, which in approximately $40 \%$ of cases are due to peritonitis (13).

The most common etiological agents of peritonitis in patients undergoing peritoneal dialysis are microorganisms of the Staphylococcus genus, and among them CNS are most frequent $(6,18)$.

Although there is evidence of a link between $S$. aureus carrier status and risk of infection $(12,16,19)$, it is not clear whether there is a relationship between the presence of CNS on the skin or nasal passage of patients and subsequent peritonitis. The aim of the present study was to verify whether endogenous sources of $S$. aureus and CNS are related to occurrence of peritonitis in patients undergoing peritoneal dialysis at the Dialysis Unit of the University Hospital, Botucatu School of Medicine, São Paulo State University (UNESP), Botucatu, São Paulo State, Brazil.

\section{PATIENTS AND METHODS}

\section{Patients}

Patients undergoing peritoneal dialysis at the Dialysis Unit of the University Hospital, Botucatu School of Medicine, UNESP, Brazil, were evaluated and those who have not presented peritonitis during the previous 3 months and have not received antibiotics in the month prior to the study were included. Those that did not fill in the study protocol or could not continue the follow-up treatment because they were transferred to another dialysis unit or to hemodialysis, or due to death, were excluded from the study. After this selection, a prospective study was carried out with 32 patients who were observed for at least 12 months.

\section{Data collection}

During selection of patients, some dada were collected such as their age, sex (male or female), race (white or non-white); associated conditions (like diabetes mellitus); peritoneal dialysis method (manual or automatic); and treatment period (in months). 
J. E. N. Batalha et al. RISK OF PERITONITIS DURING PERITONEAL DIALYSIS IN CARRIERS OF Staphylococcus aureus AND COAGULASE-NEGATIVE STAPHYLOCOCCI. J. Venom. Anim. Toxins incl. Trop. Dis., 2006, 12, 4, p. 580

\section{Definition of peritonitis}

Peritonitis was defined as the occurrence of turbid peritoneal effluent accompanied by at least one of the following signs or symptoms: abdominal pain, painful abrupt abdominal decompression, nausea, vomiting, or fever. Any of these signs alone was considered to indicate peritonitis if there was concomitantly increased peritoneal (predominantly polymorphonuclear) cellularity in the dialysis effluent to more than 100 cells $/ \mathrm{mm}^{3}$.

\section{Nasal and pericatheter skin collection}

Samples were collected from the nasal cavities and skin adjacent to the catheter. The first sampling was performed on the first day of the study; the second, after 60 days; and the third, 9-12 months after the first collection. In peritonitis patients, peritoneal effluent samples were also collected and cultured. Sterile swabs moistened with sterile saline were introduced into the anterior nasal cavity by performing delicate circular movements, a methodology directed by the preference of the patients. Samples from the pericatheter region were collected by rubbing moistened swabs over the skin adjacent to the catheter.

The collected material was stored in dry sterile tubes and immediately sent to the Bacteriology Laboratory, Department of Microbiology and Immunology, Institute of Biosciences, UNESP, Botucatu, Brazil, where they were cultured in plates containing Columbia agar base medium supplemented with $5 \%$ defibrinated sheep or rabbit blood. Then, samples were grown on Baird-Parker agar medium, which is selective for staphylococci. After incubation at $37^{\circ} \mathrm{C}$ for 24 hours, microorganisms were isolated and identified.

\section{Peritoneal effluent collection}

When peritonitis was diagnosed, $40 \mathrm{ml}$ of peritoneal effluent was aseptically collected from the patient's last drainage. It was then centrifuged and the sediment was inoculated into blood culture medium for automatic processing of incubation (BACTEC). Mcroorganisms from positive flasks were isolated and identified according to Koneman et al. (10).

\section{Staphylococcus identification}


J. E. N. Batalha et al. RISK OF PERITONITIS DURING PERITONEAL DIALYSIS IN CARRIERS OF Staphylococcus aureus AND COAGULASE-NEGATIVE STAPHYLOCOCCI. J. Venom. Anim. Toxins incl. Trop. Dis., 2006, 12, 4, p. 581

Following microbiological identification, colonies were Gram-stained to observe their purity, morphology and specific staining. After identification of their characteristics, strains were subjected to catalase tests to confirm their family as Micrococcaceae (10).

Staphylococcus genus was differentiated from Micrococcus genus based on oxidation test; glucose fermentation; resistance to bacitracin $(0.04 \mathrm{U})$, indicated by the formation of an inhibition halo of 9-mm maximum diameter; and susceptibility to furazolidone $(100 \mu \mathrm{g})$, characterized by a halo larger than $15 \mathrm{~mm}$ in diameter (4).

Coagulase test was performed to differentiate between S. aureus and CNS (10). Coagulase-negative staphylococci species were identified using a simplified method proposed by Cunha et al. (5), which consists of a battery of biochemical tests using xylose, sucrose, trehalose, mannitol, maltose and lactose, anaerobic growth in thioglycolate medium, reduction of nitrate, and production of hemolysins, urease and ornithine decarboxylase.

\section{Antibiotic susceptibility test (Kirby-Bauer method)}

The isolates susceptibility to antimicrobial drugs was tested using the agar disk diffusion technique and impregnated disks as per the National Committee for Clinical Laboratory Standards [NCCLS] (15). For inocula preparation, cultures were previously incubated for 4 to 6 hours in $\mathrm{BHI}$ broth and adjusted to a turbidity of 0.5 on the McFarland scale. The following antibiotic disks were used: penicillin G (10 IU), oxacillin $(1 \mu \mathrm{g})$, cephalothin $(30 \mu \mathrm{g})$, netilmicin $(30 \mu \mathrm{g})$, ofloxacin $(5 \mu \mathrm{g})$, and vancomycin $(30 \mu \mathrm{g})$. Drug sensitivity and resistance were interpreted according to the values defined by the NCCLS (15). The international reference strain S. aureus ATCC 25923 was used as control.

Similarity between strains isolated from different anatomical sites and those from peritoneal effluent was determined based on the inhibition halos obtained with the agar disk diffusion technique. Strains resistant to more than one of the drugs tested were classified as multidrug resistant.

\section{Determination of the minimum inhibitory concentration (E-test)}

The minimum inhibitory concentration of Staphylococcus strains was determined by the E-test ( $\mathrm{AB}$ Biodisk, Solna, Sweden), a quantitative method that uses a 
J. E. N. Batalha et al. RISK OF PERITONITIS DURING PERITONEAL DIALYSIS IN CARRIERS OF Staphylococcus aureus AND COAGULASE-NEGATIVE STAPHYLOCOCCI. J. Venom. Anim. Toxins incl. Trop. Dis., 2006, 12, 4, p. 582

transparent strip of inert plastic with drug concentrations ranging from 0.002 to 256 $\mu \mathrm{g} / \mathrm{ml}$. The following antibiotics were used: penicillin, levofloxacin, netilmicin, and vancomycin. This technique was used to interpret similarities among Staphylococcus strains isolated from peritoneal effluent of peritonitis patients and among staphylococci isolated from other sites. The proportion of strains susceptible and resistant to each drug was defined according to the NCCLS (15). The international reference strain S. aureus ATCC 29213 was used as control.

\section{Association between carrier status and occurrence of staphylococcal peritonitis}

Patients were evaluated and classified as follows: peritonitis patients nasal carrier of the Staphylococcus species that caused infection; non-peritonitis patients nasal carrier of Staphylococcus; peritonitis patients nasal non-carrier of the Staphylococcus species that caused infection; non-peritonitis patients nasal non-carrier of Staphylococcus.

Sensitivity and the positive predictive value (PPV) were analyzed when a patient presented Staphylococcus in the normal flora.

\section{Statistical analysis}

Proportions were compared using the chi-square test. To evaluate the association between carrier status and occurrence of peritonitis, sensitivity (S) and positive predictive value (PPV) were calculated using the following formulae:

$$
\begin{aligned}
& S=A /(A+C) \\
& P P V=A /(A+B),
\end{aligned}
$$

where $\mathrm{S}=$ proportion of carriers of the Staphylococcus species that caused peritonitis; PPV = probability of peritonitis being caused by the species found in the patient nasal cavity or pericatheter skin; $A=$ Staphylococcus species found in the peritoneal effluent and in the nasal cavity or pericatheter skin of the patient; $B=$ Staphylococcus species present in the nasal cavity or pericatheter skin but absent in the peritoneal effluent of the patient; $C=$ Staphylococcus species found in the peritoneal effluent but absent in the nasal cavity or pericatheter skin of the patient. 
J. E. N. Batalha et al. RISK OF PERITONITIS DURING PERITONEAL DIALYSIS IN CARRIERS OF Staphylococcus aureus AND COAGULASE-NEGATIVE STAPHYLOCOCCI. J. Venom. Anim. Toxins incl. Trop. Dis., 2006, 12, 4, p. 583

Logistic regression analysis was used to evaluate independent risk factors for peritonitis caused by endogenous Staphylococcus strains. Models were fitted using SAS v. 8.2 software through GENMOD processor.

Similarity among strains (cluster dendrograms) was analyzed in order to group strains based on the drug susceptibility tests. The UPGMA method with Euclidean distance was used (7).

\section{RESULTS}

\section{Samples}

Thirty-two patients undergoing peritoneal dialysis between January 2003 and July 2004 were studied. During this period, 96 nasal and 96 pericatheter skin samples were collected.

\section{Characteristics of the population studied}

Table 1 summarizes the characteristics of the patients studied. Age ranged from 21 to 85 years old, (mean $\pm \mathrm{SD}=54.7 \pm 17$ years old); 17 (53.1\%) patients were younger than 60 years old and 15 (46.9\%) were older than or 60 years old. There was predominance of white patients $(27 ; 84.4 \%)$; twenty were male $(62.5 \%)$, and 13 (40.6\%) were diabetic.

Twenty-four patients underwent manual dialysis technique while eight (25\%) received automated dialytic treatment. Considering the 32 patients included in the study, dialysis time (mean $\pm \mathrm{SD}$ ) was $34.6 \pm 20$ months.

\section{Staphylococcus identification}

Out of the 288 Staphylococcus strains isolated, 155 were from the nasal cavity, 122 from the skin, and 11 from peritoneal effluent of peritonitis patients. Sixty-three (21.9\%) were identified as S. aureus and 225 (78.1\%) as CNS, which included 145 (64.4\%) S. epidermidis, 34 (15.1\%) S. warneri, 24 (10.7\%) S. haemolyticus, and 22 (9.8\%) other CNS species (Table 2).

Among the 155 Staphylococcus strains isolated from the nasal cavity, 33 (21.3\%) were identified as S. aureus and $122(78.7 \%)$ as CNS, out of which S. epidermidis was the most frequent (78 isolates; $64 \%$ ), followed by $S$. warneri (21 isolates; $17.2 \%)$, and S. haemolyticus (11 isolates; 9\%). 
J. E. N. Batalha et al. RISK OF PERITONITIS DURING PERITONEAL DIALYSIS IN CARRIERS OF Staphylococcus aureus AND COAGULASE-NEGATIVE STAPHYLOCOCCI. J. Venom. Anim. Toxins incl. Trop. Dis., 2006, 12, 4, p. 584

From the 122 strains isolated from the pericatheter skin, 27 (22.1\%) were identified as S. aureus and $95(77.9 \%)$ as CNS. The most frequent CNS were S. epidermidis (61 isolates; 64.2\%), S. haemolyticus (13 isolates; 13.7\%), and S. warneri (11 isolates; $11.6 \%)$.

Out of the 11 peritonitis cases, three (27.3\%) were caused by $S$. aureus and eight (72.7\%) by CNS, including S. epidermidis (6 cases; 75\%) and S. warneri (2 cases; 25\%) (Table 2).

\section{Frequency of patients with multidrug-resistant Staphylococcus strains}

In vitro resistance to more than one antimicrobial drug was observed in strains from $25(78 \%)$ patients. Multidrug-resistant S. epidermidis strains were detected in 17 (53.1\%) patients; other multidrug-resistant CNS were found in six (18.75\%) patients, and S. aureus strains resistant to more than one drug were observed in two $(6.2 \%)$ patients. Difference among these groups was significant $(p<0.05)$.

\section{Evaluation of risk factors for staphylococcal peritonitis}

Analysis of risk factors revealed a greater predisposition to infection by $S$. aureus strains in older $(p=0.05)$ and non-white $(p=0.05)$ patients. Among the patients colonized with S. epidermidis strains, peritonitis was only observed in those who were carrier of multidrug-resistant strains $(p=0.05)$.

\section{Association between carrier status and occurrence of staphylococcal peritonitis}

Nine patients presented 11 staphylococcal peritonitis cases, of which two occurred during the observation period. Association analysis showed that eight patients, who continued with some Staphylococcus species, developed peritonitis, while one patient developed peritonitis due to a Staphylococcus species that was not present in the nasal cavity or even on the skin. Twenty-three patients were classified as nasal carriers of Staphylococcus and did not develop peritonitis during the 12 months of the study period. None of the patients who did not develop peritonitis were classified as nasal non-carriers of Staphylococcus; at the end of the study, some Staphylococcus species were detected in their nasal cavity.

In Staphylococcus carriers, PPV was 26\%. Sensitivity of patients who developed peritonitis was $89 \%$. Specificity and negative predictive value were zero. 
J. E. N. Batalha et al. RISK OF PERITONITIS DURING PERITONEAL DIALYSIS IN CARRIERS OF Staphylococcus aureus AND COAGULASE-NEGATIVE STAPHYLOCOCCI. J. Venom. Anim. Toxins incl. Trop. Dis., 2006, 12, 4, p. 585

Figures 2-6 show dendrograms drawn based on the inhibition halos obtained using the agar disk diffusion technique for visualization of clusters of Staphylococcus strains.

Figure 2 shows dendrograms for $S$. aureus strains isolated from peritoneal effluent, anterior nasal cavity and pericatheter skin of two patients who developed peritonitis. In patients 19 and 22, there was grouping, therefore similarity, between the strain isolated from peritoneal effluent and that isolated from the anterior nasal cavity and pericatheter skin. Inhibition halos obtained for the strain isolated from the skin and peritoneal effluent of patient 22 were identical for all drugs tested, while a difference of $1 \mathrm{~mm}$ in the inhibition halos was observed for one of the drugs tested in patient 19. Dendrograms in Figures 3-6 included CNS strains isolated from peritoneal effluent, anterior nasal cavity and pericatheter skin of six patients who developed peritonitis, and showed that groupings (similarities) between strains from peritoneal effluent and those from the other collection sites were variable; the greatest similarity was observed between strains isolated from the anterior nasal cavity in patient 28 and that isolated from the pericatheter skin in patient 6 (Figure 3). In patient 28 , the CNS strain isolated from the nasal cavity, which grouped with the agent of peritonitis, had a difference of $1 \mathrm{~mm}$ in its inhibition halos with three of the six drugs tested (Figure 3). In patient 6 , the difference in inhibition halos was $1 \mathrm{~mm}$ with two drugs and $2 \mathrm{~mm}$ with three drugs (Figure 3). In patient 8 , the difference in inhibition halos ranged from 3 to $4 \mathrm{~mm}$, which indicates a slightly more distant grouping (Figure 4). In the remaining patients the possibility of grouping was still more distant, with a difference in inhibition halos of up to $9 \mathrm{~mm}$ between CNS isolated from peritoneal effluent and those from other sites [anterior nasal cavity samples in patient 10 or anterior nasal cavity and pericatheter skin, simultaneously, in patient 31] (Figure 5).

In patient 2, no grouping was observed between strains isolated from peritoneal effluent and strains isolated from other sites. Only a distant grouping was noticed; therefore, no similarity among strains was observed and very different inhibition halos were verified for all drugs tested (Figure 6).

Analysis of dendrograms drawn with the values obtained in the E-test for $S$. aureus and CNS confirmed the results obtained in the agar disk diffusion method (data not shown). 
J. E. N. Batalha et al. RISK OF PERITONITIS DURING PERITONEAL DIALYSIS IN CARRIERS OF Staphylococcus aureus AND COAGULASE-NEGATIVE STAPHYLOCOCCI. J. Venom. Anim. Toxins incl. Trop. Dis., 2006, 12, 4, p. 586

Table 1: Characteristics of the 32 patients included in the study.

\begin{tabular}{lcc}
\hline & Number & \\
\hline Age (years), mean \pm SD & (\%) & \\
Sex & $54.75 \pm 17$ & \\
Male & 20 & $(62.5)$ \\
Female & 12 & $(37.5)$ \\
Race & & $(84.4)^{\star}$ \\
White & 27 & $(15.6)$ \\
Non-white & 5 & $(40.6)$ \\
Diabetes mellitus & & $(59.4)$ \\
Yes & 13 & \\
No & 19 & $(75)^{\star}$ \\
Dialysis technique & & $(25)$ \\
Manual & 24 & \\
Automated & 8 & \\
\hline
\end{tabular}

$\mathrm{SD}=$ standard deviation. ${ }^{*} p<0.05$.

Table 2: Distribution of Staphylococcus strains isolated from the nasal cavity, pericatheter skin and peritoneal effluent of 32 patients undergoing peritoneal dialysis.

\begin{tabular}{lcccc}
\hline Species & \multicolumn{4}{c}{ Collection site } \\
\hline S. aureus & Nasal cavity & Skin & Peritoneal effluent & Total \\
S. epidermidis & 78 & 27 & 3 & 63 \\
S. warneri & 21 & 61 & 6 & 145 \\
S. haemolyticus & 11 & 11 & 2 & 34 \\
S. saprophyticus & 4 & 2 & 0 & 24 \\
S. capitis & 3 & 2 & 0 & 6 \\
S. simulans & 3 & 2 & 0 & 5 \\
S. lugdunensis & 1 & 2 & 0 & 5 \\
S. hominis & 0 & 2 & 0 & 3 \\
S. schleiferi & 1 & 0 & 0 & 2 \\
\hline Total & 155 & 122 & 0 & 1 \\
\hline
\end{tabular}


J. E. N. Batalha et al. RISK OF PERITONITIS DURING PERITONEAL DIALYSIS IN CARRIERS OF Staphylococcus aureus AND COAGULASE-NEGATIVE STAPHYLOCOCCI. J. Venom. Anim. Toxins incl. Trop. Dis., 2006, 12, 4, p. 587

\begin{tabular}{|c|c|c|c|}
\hline & & \multicolumn{2}{|c|}{$\begin{array}{l}\text { Occurrence of peritonitis by Staphylococcus } \\
(\mathrm{n}=9)\end{array}$} \\
\hline & & yes & no \\
\hline \multirow{2}{*}{$\begin{array}{l}\text { Nasal carrier of a species of } \\
\text { Staphylococcus which caused } \\
\text { peritonitis }\end{array}$} & yes & $n=8$ & $n=23$ \\
\hline & no & $n=1$ & $n=0$ \\
\hline
\end{tabular}

Figure 1: Association between carrier status and occurrence of staphylococcal peritonitis in 32 patients undergoing peritoneal dialysis.
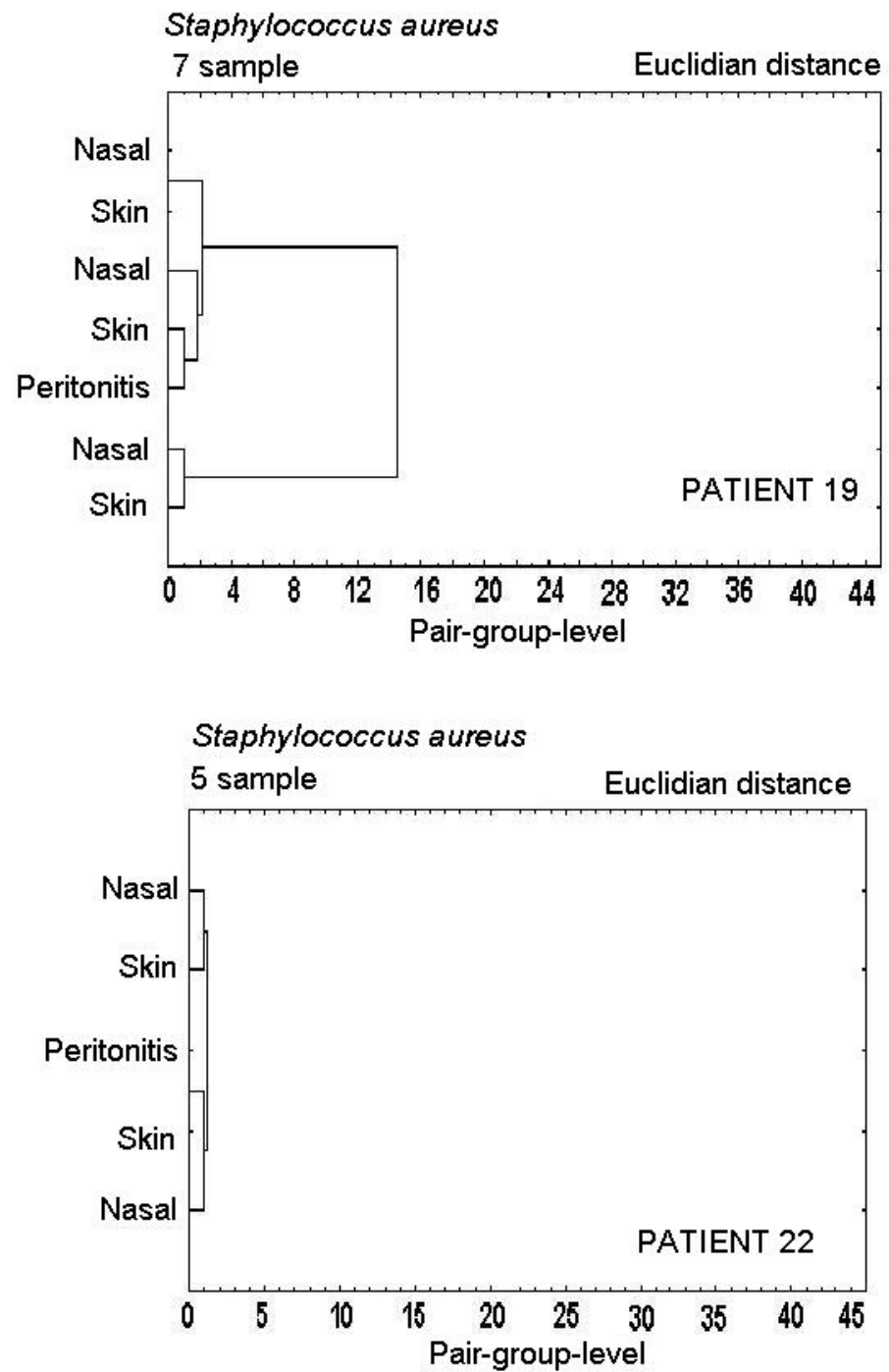

Figure 2: Similarity dendrograms drawn based on inhibition halos obtained by using the agar disk diffusion technique for $S$. aureus isolated from the nasal cavity, pericatheter skin and peritoneal effluent of two patients undergoing peritoneal dialysis. 
J. E. N. Batalha et al. RISK OF PERITONITIS DURING PERITONEAL DIALYSIS IN CARRIERS OF Staphylococcus aureus AND COAGULASE-NEGATIVE STAPHYLOCOCCI. J. Venom. Anim. Toxins incl. Trop. Dis., 2006, 12, 4, p. 588

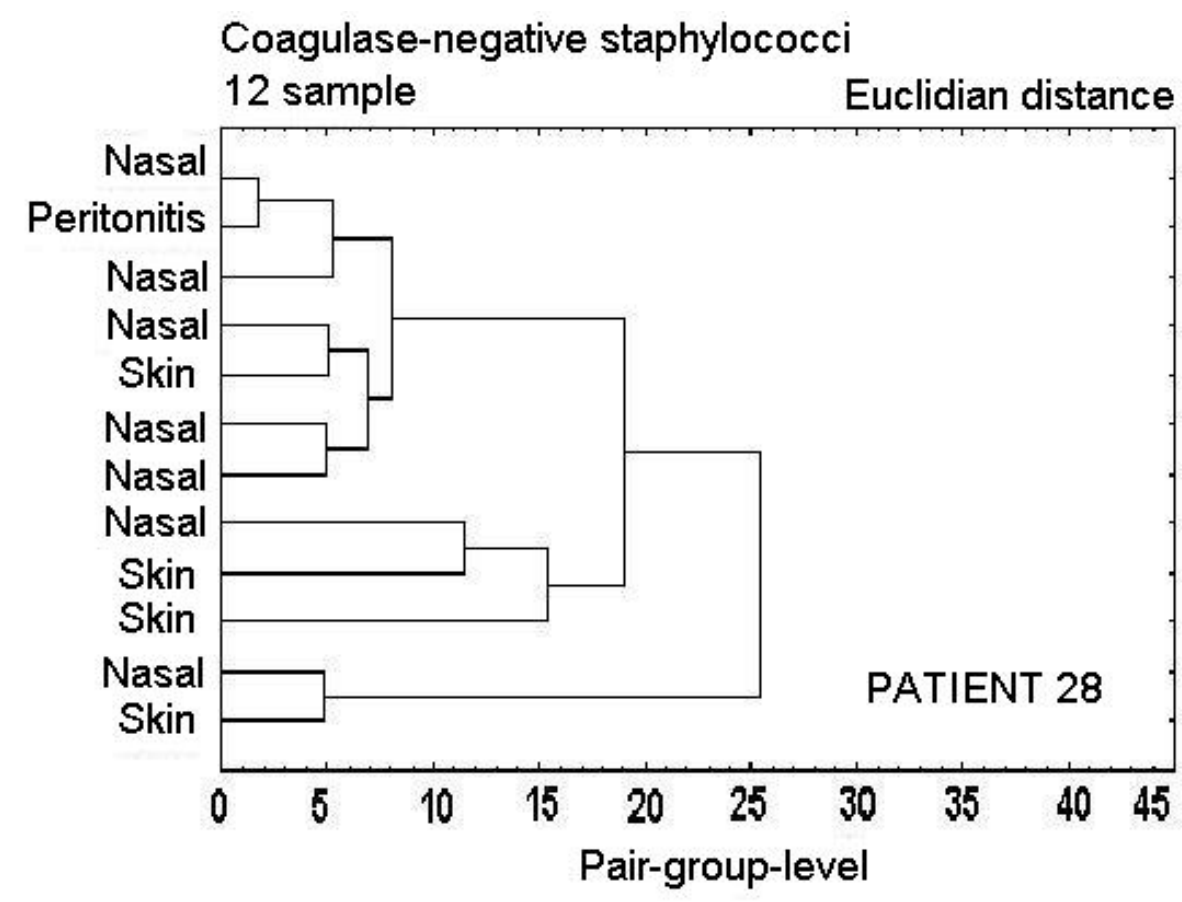

Coagulase-negative staphylococci

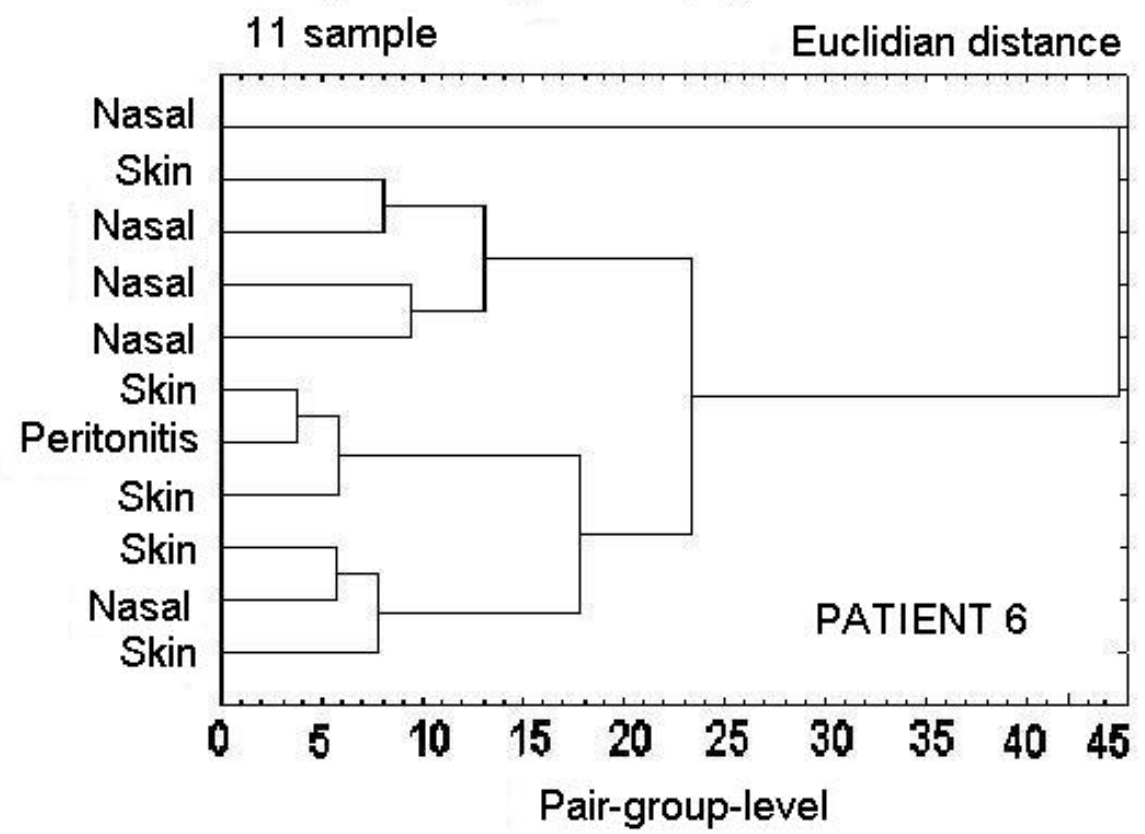

Figure 3: Similarity dendrograms drawn based on inhibition halos obtained by using the agar disk diffusion technique for coagulase-negative staphylococci isolated from the nasal cavity, pericatheter skin and peritoneal effluent of two patients undergoing peritoneal dialysis. 
J. E. N. Batalha et al. RISK OF PERITONITIS DURING PERITONEAL DIALYSIS IN CARRIERS OF Staphylococcus aureus AND COAGULASE-NEGATIVE STAPHYLOCOCCI. J. Venom. Anim. Toxins incl. Trop. Dis., 2006, 12, 4, p. 589

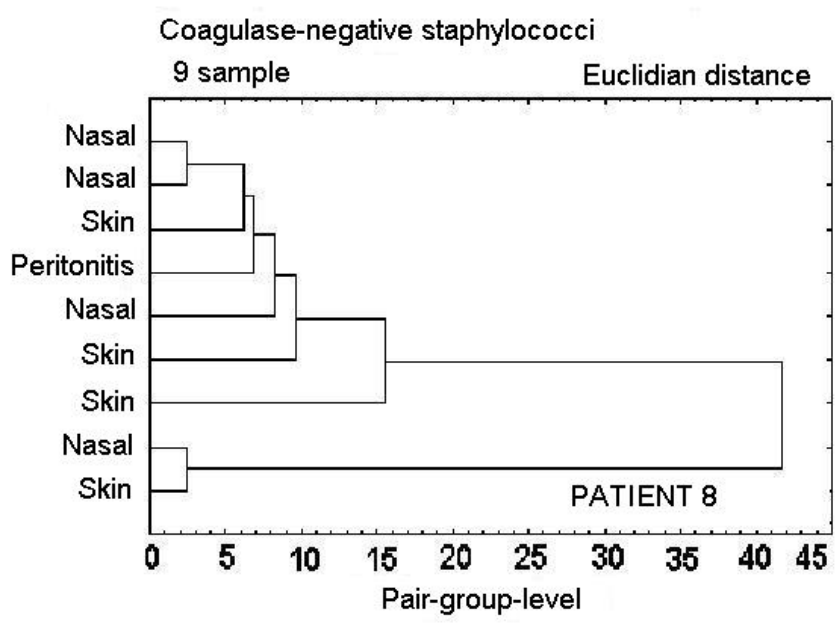

Figure 4: Similarity dendrogram drawn based on inhibition halos obtained by using the agar disk diffusion technique for coagulase-negative staphylococci isolated from the nasal cavity, pericatheter skin and peritoneal effluent of one patient undergoing peritoneal dialysis.
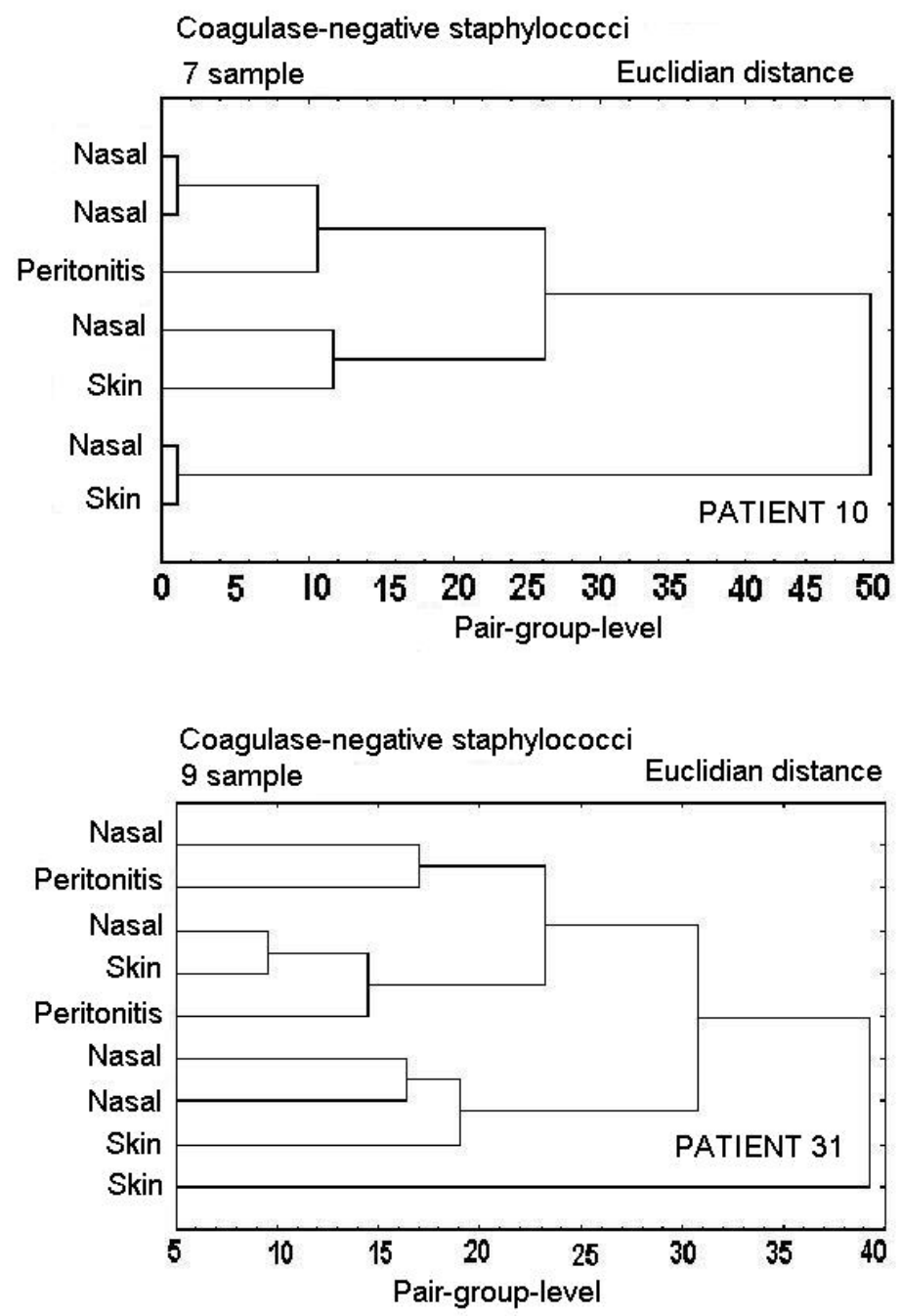

Figure 5: Similarity dendrograms drawn based on inhibition halos obtained by using the agar disk diffusion technique for coagulase-negative staphylococci isolated from the nasal cavity, pericatheter skin and peritoneal effluent of two patients undergoing peritoneal dialysis. 
J. E. N. Batalha et al. RISK OF PERITONITIS DURING PERITONEAL DIALYSIS IN CARRIERS OF Staphylococcus aureus AND COAGULASE-NEGATIVE STAPHYLOCOCCI. J. Venom. Anim. Toxins incl. Trop. Dis., 2006, 12, 4, p. 590

Coagulase-negative staphylococci

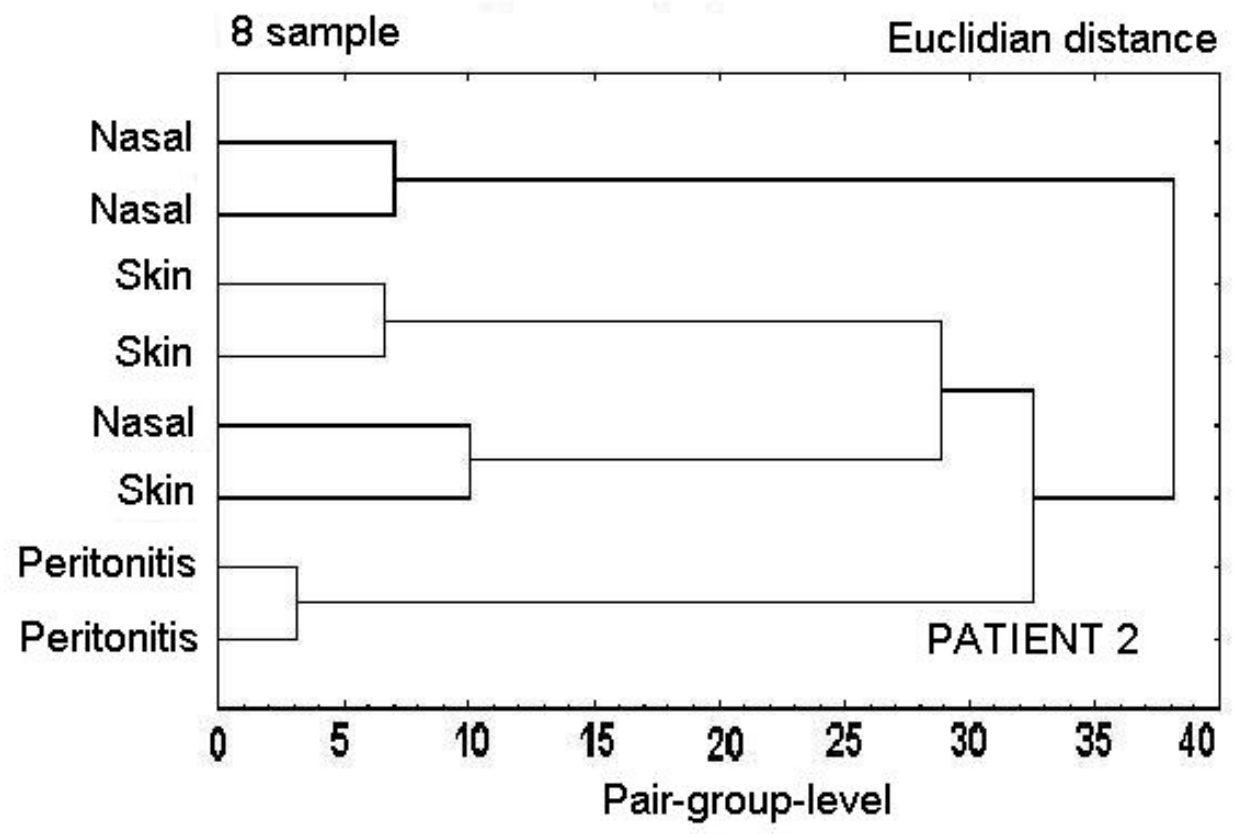

Figure 6: Similarity dendrogram drawn based on inhibition halos obtained by using the agar disk diffusion technique for coagulase-negative staphylococci isolated from the nasal cavity, pericatheter skin and peritoneal effluent of one patient undergoing peritoneal dialysis.

\section{DISCUSSION}

Carriers of $S$. aureus in the nasal cavities and pericatheter skin are considered to be at higher risk of developing peritonitis $(12,16,19)$. However, it is not clear whether the presence of CNS on the skin or in the nasal cavities of patients is related to subsequent peritonitis.

The present study observed 32 patients undergoing peritoneal dialysis for 18 months to determine the Staphylococcus species present in their nasal cavity, pericatheter skin and peritoneal effluent as well as the similarity among strains isolated from these different anatomical sites. The population studied consisted of adult individuals, predominantly whites undergoing manual dialysis.

Out of the 288 Staphylococcus strains isolated, $53.8 \%$ were found in the nasal cavity, $42.4 \%$ on the skin and $3.8 \%$ in the peritoneal effluent of patients who developed peritonitis during the study. The Staphylococcus species most frequently found were CNS (78.1\%), followed by S. aureus (21.9\%), which are similar to the results reported by Eisenberg et al. (6). 
J. E. N. Batalha et al. RISK OF PERITONITIS DURING PERITONEAL DIALYSIS IN CARRIERS OF Staphylococcus aureus AND COAGULASE-NEGATIVE STAPHYLOCOCCI. J. Venom. Anim. Toxins incl. Trop. Dis., 2006, 12, 4, p. 591

Among CNS, S. epidermidis was the species most frequently isolated (64.4\%), followed by S. warneri, S. haemolyticus and other species. Since the identification of CNS is not a routine procedure, few studies have identified species isolated from patients on peritoneal dialysis. In the study by Eisenberg et al. (6), S. epidermidis accounted for $75 \%$ of the CNS isolated. Identification of Staphylococcus species is not only epidemiologically important but may also contribute to the correlation between species with pathogenic potential and their susceptibility profile to antimicrobial drugs.

Although CNS infections are considered to be associated with few unforeseen complications and usually show a benign course, alarming rates of relapse in cases of peritonitis caused by these microorganisms have been reported (20).

To determine the relationship between carrier status and occurrence of peritonitis, various methods have been proposed in an attempt to establish similarity between strains isolated from nasal cavities and/or other extraperitoneal anatomical sites and those isolated from peritoneal effluent $(1,9,16)$. The main objective of analyzing the resistance profile to antimicrobial drugs using the agar diffusion technique was to determine similarity among strains isolated from the skin, nasal cavity and peritoneal effluent of patients who developed peritonitis during the study period. In addition, the E-test method was used to confirm the data obtained and to increase the analyses reliability. Dendrograms were also drawn with the aim of grouping strains based on the results of drug susceptibility tests, which permitted visual evaluation of proximity among strains and showed grouping of samples belonging to extraperitoneal sites and the causes of infection.

Among the peritonitis cases studied, $73 \%$ were caused by CNS, $75 \%$ by $S$. epidermidis, and the remaining by $S$. warneri. Similar results were reported by West et al. (20), who analyzed 41 cases of CNS-induced peritonitis, from which $S$. epidermidis was identified in 70\%, and S. warneri in 7\%. These authors also reported that CNS were responsible for $53.2 \%$ of peritonitis cases, $82.9 \%$ of them being caused by $S$. epidermidis. These frequencies agree with other studies that considered this species to be of high clinical relevance and to be predominantly found on the skin and nasal cavity of humans. These results suggest that the incidence of infection by these microorganisms reflects contamination of the dialysis fluid with organisms present on the body surface of the patients. 
J. E. N. Batalha et al. RISK OF PERITONITIS DURING PERITONEAL DIALYSIS IN CARRIERS OF Staphylococcus aureus AND COAGULASE-NEGATIVE STAPHYLOCOCCI. J. Venom. Anim. Toxins incl. Trop. Dis., 2006, 12, 4, p. 592

Fontán et al. (8), studying 146 cases of peritonitis, found that two of every three cases caused by $S$. aureus were associated with the presence of this species in the patient nasal cavity. According to these authors, the data obtained supported the concept that Staphylococcus carriers present a significant risk of developing peritonitis, although studies such as that by Lubrich-Birkner et al. (11) did not find a correlation between Staphylococcus carrier status and infection by the colonizing species. In the present study, the same species was isolated from the flora in two $(66 \%)$ of the three cases caused by $S$. aureus. The same species in normal flora was observed in the six cases of peritonitis caused by S. epidermidis; two cases (34\%) showed high similarity, and in three $(50 \%)$ cases, the possibility of grouping was remote. However, in two cases of peritonitis caused by $S$. warneri, the isolated strains did not present similarities, although the same species was isolated from the normal flora.

Statistical analysis revealed a predisposition to infection in patients colonized with multidrug-resistant S. epidermidis strains. According to Archer and Climo (3), there is an association between the increased frequency of CNS in the etiology of infections and the resistance of these microorganisms to antimicrobial agents. Strains isolated from clinical samples have frequently shown resistance to commonly used antibiotics (9). Investigators have emphasized that these microorganisms are reservoirs of various resistance genes since they correspond to the largest proportion of the skin microflora and, consequently, are more subject to the selective pressure of commonly used antimicrobial drugs (2). The high rate of transmission of plasmids between these microorganisms and the abusive use of antimicrobial drugs has markedly contributed to the selection of multidrug-resistant strains and to the transference of resistance genes $(14,17)$.

The chance of isolating the same species that caused infection from the flora of patients who presented episodes of staphylococcal peritonitis was $89 \%$. Since the population studied included carriers of several Staphylococcus species, the estimated probability of occurrence of peritonitis caused by the same species found in the nasal cavity or pericatheter skin of the patient was $26 \%$.

Results of the present study reinforce the influence of an endogenous source of $S$. epidermidis on the occurrence of peritonitis in peritoneal dialysis patients as has been observed for $S$. aureus. 
J. E. N. Batalha et al. RISK OF PERITONITIS DURING PERITONEAL DIALYSIS IN CARRIERS OF Staphylococcus aureus AND COAGULASE-NEGATIVE STAPHYLOCOCCI. J. Venom. Anim. Toxins incl. Trop. Dis., 2006, 12, 4, p. 593

\section{REFERENCES}

1 AMATO D., VENTURA M., MiRANDA G., LEAÑOS B., ALCÁNTARA G., HURTADO ME., PANIAGUA R. Staphylococcal peritonitis in continuous ambulatory peritoneal dialysis: colonization with identical strains at exit site, nose and hands. Am. J. Kidney Dis., 2001, 37, 43-8.

2 ARCHER GL. Molecular epidemiology of multiresistant Staphylococcus epidermidis. J. Antimicrobiol. Chemother., 1988, 21, 133-8.

3 ARCHER GL., CLIMO MW. Antimicrobial susceptibility of coagulase-negative staphylococci. Antimicrobiol. Agents Chemother., 1994, 38, 2231-7.

4 BAKER JS. Comparison of various methods for differentiation of staphylococci and micrococci. J. Clin. Microbiol., 1984, 19, 875-9.

5 CUNHA MLRS., SINZATO YK., SILVEIRA LVA. Comparison of methods for the identification of coagulase-negative staphylococcus. Mem. Inst. Oswaldo Cruz, 2004, 99, 855-60.

6 EISENBERG ES., AMBALU MSG., ANING V., SOEIRO R. Colonization of skin and development of peritonitis due to coagulase-negative staphylococci in patients undergoing peritoneal dialysis. J. Infect. Dis., 1987, 156, 478-82.

7 EVERITT, BS. Cluster analysis. London: Heineman Educational Books, 1979.

8 FONTÁN MP., CARMONA AR., ROSALES M., FALCÓN TG., VALDÉS F. Incidence and clinical significance of nasal and pericatheter colonization by Gram-negative bacteria among patients undergoing chronic peritoneal dialysis. Nephrol. Dial. Transplant., 2002, 17, 118-22.

9 GROSSERODE MH., WENZEL RP. The continuing importance of staphylococci as major hospital pathogens. J. Hosp. Infect., 1991, 19, 3-17.

10 KONEMAN EW., ALLEN SD., JANDA WM., SCHRECKENBERGER PC., WINN JR WC. Color atlas and textbook of diagnostic microbiology. Philadelphia: Lippincott, 1997.

11 LUBRICH-BIRKNER I., SCHOLLEMEYER P., BOHLER J. Carrier-status for nasal staphylococci does not predict infection: CAPD patients. Adv. Perit. Dial., 1994, 10, 154-7.

12 LUZAR MA., COLES GA., FALLER B., SLINGENEYER A., DAH DG., BRIAT C., WONE C., KNEFATI Y., KESSLER M., PELUSO F. Staphylococcus aureus nasal carriage and infection in patients on continuous ambulatory peritoneal dialysis. N. Engl. J. Med., 1990, 322, 505-9. 
J. E. N. Batalha et al. RISK OF PERITONITIS DURING PERITONEAL DIALYSIS IN CARRIERS OF Staphylococcus aureus AND COAGULASE-NEGATIVE STAPHYLOCOCCI. J. Venom. Anim. Toxins incl. Trop. Dis., 2006, 12, 4, p. 594

13 MAIORCA R., VONESH EF., CAVALLI P., DE VECCHI A., GIANGRANDE A., LA GRECA G., SCARPIONI LL., BRAGANTINI L., CANCARINI GC, CANTAlupPI A., CAStelnovo C., CAStiglioni A., POISETTI P., VIGLINO G. A multicenter, selection-adjusted comparison of patient and technique survivals on CAPD and hemodialysis. Perit. Dial. Int., 1991, 11, 11827.

14 McDONNELL RW., SWEENEY HM., COHEN S. Conjugational transfer of gentamicin resistance plasmids intra- and interspecifically in Staphylococcus aureus and Staphylococcus epidermidis. Antimicrob. Agents Chemother., 1983, 23, 151-60.

15 NATIONAL COMMITTEE FOR CLINICAL LABORATORY STANDARDS. Performance standards for antimicrobial disk susceptibility tests. Pennsylvania: NCCLS, M100-S12, 2002.

16 PIgNATARI A., PFALlER M., HOLLIS R., SESSO R., LEME I., HERWALDT L. Staphylococcus aureus colonization and infection in patients on continuous ambulatory peritoneal dialysis. J. Clin. Microbiol., 1990, 28, 1898-902.

17 SCHABERG DR., CULVER DH., GAYNE, RP. Major trends in the microbial etiology of nosocomial infection. Am. J. Med., 1991, 91, 72-5.

18 SCHNITZLER N., MEILICKE R., CONRADS G., FRANK D., HAASE G. Staphylococcus lugdunensis: report of a case of peritonitis and easy-toperform screening strategy. J. Clin. Microbiol., 1998, 36, 812-3.

19 SESSO R., DRAIBE S., CASTELO A., SATO I., LEME I., BARBOSA D., RAMOS O. Staphylococcus aureus skin carriage and development of peritonitis in patients on continuous ambulatory peritoneal dialysis. Clin. Nephrol., 1989, $31,264-8$.

20 WEST TE., WALSHE JJ., KROL CP., AMSTERDAM D. Staphylococcal peritonitis in patients on continuous peritoneal dialysis. J. Clin. Microbiol., 1986, 23, 809-12. 